\title{
Migration of Intraocular Silicone Oil from the Vitreous Cavity into the Upper Eyelid Causing Ptosis
}

\author{
Yuzo Deguchi ${ }^{a} \quad$ Takatoshi Maeno $^{a} \quad$ Yuichi Hori $^{\mathrm{a}} \quad$ Nobuyuki Hiruta $^{\mathrm{b}}$ \\ Daisuke Sasai $^{\text {b }}$ Yukihiro Sato $^{c}$ \\ Departments of ${ }^{a}$ Ophthalmology and ${ }^{b}$ Surgical Pathology, Toho University Sakura Medical \\ Center, Chiba, and ' Department of Diabetes Center, Jichi Medical University, \\ Tochigi, Japan
}

\section{Key Words}

Migration of silicone oil · Upper eyelid · Vitrectomy · Scleral buckling · Postoperative complication · Ptosis

\begin{abstract}
Introduction: To report a case in which intraocular silicone oil migrated into the upper eyelid and caused ptosis. Methods: A 65-year-old woman presented with proliferative vitreoretinopathy in the right eye. Vitrectomies, injection of silicone oil and encircling were performed. Two months after the last operation, swelling of her right eyelid occurred. Result: Magnetic resonance imaging revealed moisture in the palpebral fat tissue. We incised the bulbar conjunctiva and confirmed silicone oil leakage from the vitreous cavity through the scleral button hole of the encircling suture. Postoperatively, the right upper eyelid swelling decreased. Histopathologically, dense macrophage infiltration was seen in the palpebral tissues. Conclusions: We report a rare case with a postoperative complication caused by silicone oil. In cases with swelling of the eyelid and decreased silicon oil in the vitreous cavity postoperatively, clinicians should consider the possibility of silicone oil leakage.
\end{abstract}

(c) 2014 S. Karger AG, Basel

\section{Introduction}

Silicone oil is commonly used for intraocular tamponade in vitreoretinal surgery for severe retinal detachments. There are several reports of intraocular silicone oil migration into the subconjunctival space [1-5], the orbit [5-7] and even the central nervous system [8-

Yuzo Deguchi, MD

Department of Ophthalmology

Toho University Sakura Medical Center

564-1 Shimoshizu, Sakura, Chiba 285-8741 (Japan)

E-Mail dgz0402dgz@yahoo.co.jp 
Deguchi et al.: Migration of Intraocular Silicone Oil from the Vitreous Cavity into the Upper Eyelid Causing Ptosis

11]. However, to our knowledge, there are only two reports, describing three cases in total, with intraocular silicone oil migration into the upper eyelid causing ptosis as a postoperative complication $[12,13]$. Herein, we report a case with this rare complication.

\section{Case Report}

A 65-year-old woman presented with proliferative vitreoretinopathy in her right eye. Vitrectomy using a 20-gauge system with suturing of the scleral entry sites and placement of an encircling silicone band (No. 240, No. 270; MIRA Inc., Waltham, Mass., USA) were performed. During surgery, an iatrogenic retinal break was accidentally made at the inferior temporal retina. At the completion of surgery, silicone oil (SILIKONTM 1000; Alcon Laboratories, Fort Worth, Tex., USA) with a 1,000-centistoke viscosity was injected into the vitreous cavity to achieve tamponade. Two years after the first surgery, retinal detachment recurred with a reopening of the iatrogenic retinal break in her right eye at the inferior quadrant. The 20-gauge vitrectomy procedure was repeated and a wide silicone band (No. 287, MIRA Inc.) was placed at the inferior quadrant followed by reinjection of silicone oil. Two months after the last operation, swelling of her right eyelid occurred. We suspected a postoperative bacterial infection and prescribed topical (Moxifloxacin, Cefmenoxime) and systemic (Gatifloxacin $30 \mathrm{mg} /$ day) antibacterial therapy. Three months after the last operation, bestcorrected visual acuity was 2/200 in her right eye, and intraocular pressure was $21 \mathrm{~mm} \mathrm{Hg}$. Her right upper eyelid swelling did not respond to the antibiotic administration, showing persistent erythema and ptosis (fig. 1a). Silicone oil-like material was recognized under the upper bulbar conjunctiva. We confirmed that the silicone oil in the vitreous cavity had decreased by $70 \%$. We thus speculated that the silicone oil had leaked from the vitreous cavity and migrated into the subconjunctival space and the upper eyelid. Magnetic resonance imaging revealed fluid in the upper palpebral tissues, suggesting edema or inflammation (fig. 2).

We suspected that silicone oil was present in the eyelid. We incised her right upper eyelid skin near the eyelid margin and confirmed that there was silicone oil in the palpebral tissues. We performed surgery to remove the silicone oil from the vitreous cavity. We incised the bulbar conjunctiva 360 degrees parallel to the limbus, and confirmed silicone oil leakage from the vitreous cavity through the scleral button hole of the encircling suture at the inferior quadrant. Postoperatively, the right upper eyelid swelling decreased (fig. 1b). However, as her ptosis did not improve, plastic surgery was performed on the right upper lid. During this cosmetic procedure, edema of all layers of the eyelid as well as granulomatous changes in the subcutaneous fat and fibrous changes in the orbicularis oculi muscle were recognized. After the plastic surgery, the right upper lid abnormality resolved (fig. 1c). Histopathologically, infiltrations of numerous macrophages containing several clear vacuoles of various sizes, consistent with silicone deposits, were observed in the dermis and subcutaneous fat (fig. 3).

\section{Discussion}

Our findings indicated that silicone oil had leaked out of the vitreous cavity and migrated into the subconjunctival space and the upper eyelid. We suggest that the silicone oil initially leaked into the subretinal space through the iatrogenic retinal break. This was followed by silicone oil leakage into the peribulbar space through the perforation site of the 
Deguchi et al.: Migration of Intraocular Silicone Oil from the Vitreous Cavity into the Upper Eyelid Causing Ptosis

scleral suture. Finally, the silicone oil migrated from the peribulbar space into the subconjunctival space and the upper eyelid. There was no apparent evidence of a continuous path from the peribulbar space near the scleral button hole of the encircling suture to the upper eyelid. However, after silicone oil removal, this patient underwent corrective a plastic surgery for ptosis of the right upper eyelid. During this procedure, edema of all layers of the eyelid, with granulomatous changes of subcutaneous fat and fibrous changes of the orbicularis oculi muscle were recognized. Therefore, we speculated that silicone oil had migrated through all layers of the eyelid.

Like all three previously reported cases, our patient showed upper eyelid swelling and ptosis $[12,13]$. The Lockwood ligament (i.e., thickened lower part of the Tenon capsule) might act as a diaphragm between the peribulbar space and the lower eyelid [14], preventing silicone oil from migrating to the lower eyelid.

There are several reports describing silicone oil migrating out of the eye under various conditions [1-13]. Srinivascan et al. [4] described silicone oil leakage through the scleral entry site of a vitrectomy. In the case described by Quintyn et al. [12], silicone oil migrated through a transscleral subretinal drainage site. The presence of postoperative ocular hypertension contributed to this complication in two cases. Our present patient had silicone oil leakage from the vitreous cavity into the palpebral tissues, and her upper eyelid showed swelling, erythema and ptosis. The silicone oil then triggered granulation of palpebral tissues. Silicone oil is known to cause only minor inflammatory reactions. However, it can reportedly trigger tissue granulation in cases with silicone oil leakage from the vitreous cavity $[4,7,12,13]$. We assumed that medical grade silicone oil might have exerted toxic effects leading to a silicone-induced inflammatory reaction, thereby producing palpebral tissue granulation in our present case. Thus, we recommend that in cases with swelling of the eyelid and decreased silicon oil in the vitreous cavity after undergoing silicone oil tamponade, clinicians consider the complication of silicone oil leakage from the vitreous cavity.

\section{Disclosure Statement}

No financial support was received for this submission. The authors have no conflicts of interest to disclose.

\section{References}

1 Hyung AM, Min JP: Subconjunctival silicone oil drainage through the Molteno implant. Korean J Ophthalmol 1998;12:73-75.

-2 Friberg TR, Fanous MM: Migration of intravitreal silicone oil through a Baerveldt tube into the subconjunctival space. Semin Ophthalmol 2004;19:107-108.

-3 Chan CK, Tarasewicz DG, Lin SG: Subconjunctival migration of silicone oil through a Baerveldt pars plana glaucoma implant. Br J Ophthalmol 2005;89:240-241.

-4 Srinivascan S, Singh AK, Desai SP, Talbot JF, Parsons MA: Foreign body episcleral granulomas complicating intravitreal silicone oil tamponade. A clinicopathological study. Ophthalmology 2003;110:1837-1840.

5 Nazemi PP, Chong LP, Varma R, Burnstine MA: Migration of intraocular silicone oil into the subconjunctival space and orbit through an Ahmed glaucoma valve. Am J Ophthalmol 2000;129:685-688.

-6 Cooke CA, White ST, Best RM and Walsh MY: Silicone oil migration causing increasing proptosis 13 years after retinal surgery. Eye 2006;20:621-623.

-7 Couch SM, Harocopos GJ, Holds JB: Orbital silicone oil granuloma discovered during enucleation. Arch Ophthalmol 2012;130:1083-1085.

-8 Eller AW, Friberg TR, Mah F: Migration of silicone oil into the brain. Am J Ophthalmol 2000;129:685-688. 
Case Reports in

Ophthalmology

\begin{tabular}{l|l}
\hline Case Rep Ophthalmol 2014;5:226-230 \\
\hline DOI: 10.1159/000365647 & $\begin{array}{l}\text { ○ 2014 S. Karger AG, Basel } \\
\text { www.karger.com/cop }\end{array}$ \\
\hline
\end{tabular}

Deguchi et al:: Migration of Intraocular Silicone Oil from the Vitreous Cavity into the Upper Eyelid Causing Ptosis

9 Fangtian D, Rongping D, Lin Z, Weihong Y: Migration of intraocular silicone into the cerebral ventricles. Am J Ophthalmol 2005;140:156-158.

10 Yu JT, Apte RS: A case of intravitreal silicone oil migration to the central nervous system. Retina 2005;25:791-793.

11 Eckle D, Kampic A, Hintschich C, Haritoglou C, Tonn JC, Uhl E, Lienemann A: Visual field defect in association with chiasmal migration of intraocular silicone oil. Br J Ophthalmol 2005;89:918-920.

12 Quintyn JC, Genevois 0, Ranty ML, Retout A: Silicone oil migration in the eyelid after vitrectomy for retinal detachment. Am J Ophthalmol 2003;136:540-542.

13 Donker DLT, Paridaens D, Mooy CM, van den Bosch WA: Blepharoptosis and upper eyelid swelling due to lipogranulomatous inflammation caused by silicone oil. Am J Ophthalmol 2005;140:934-936.

14 Warwick R: Extraocular Muscles, ed 7, rev. London, H.K. Lewis \& Co. Ltd., 1976.
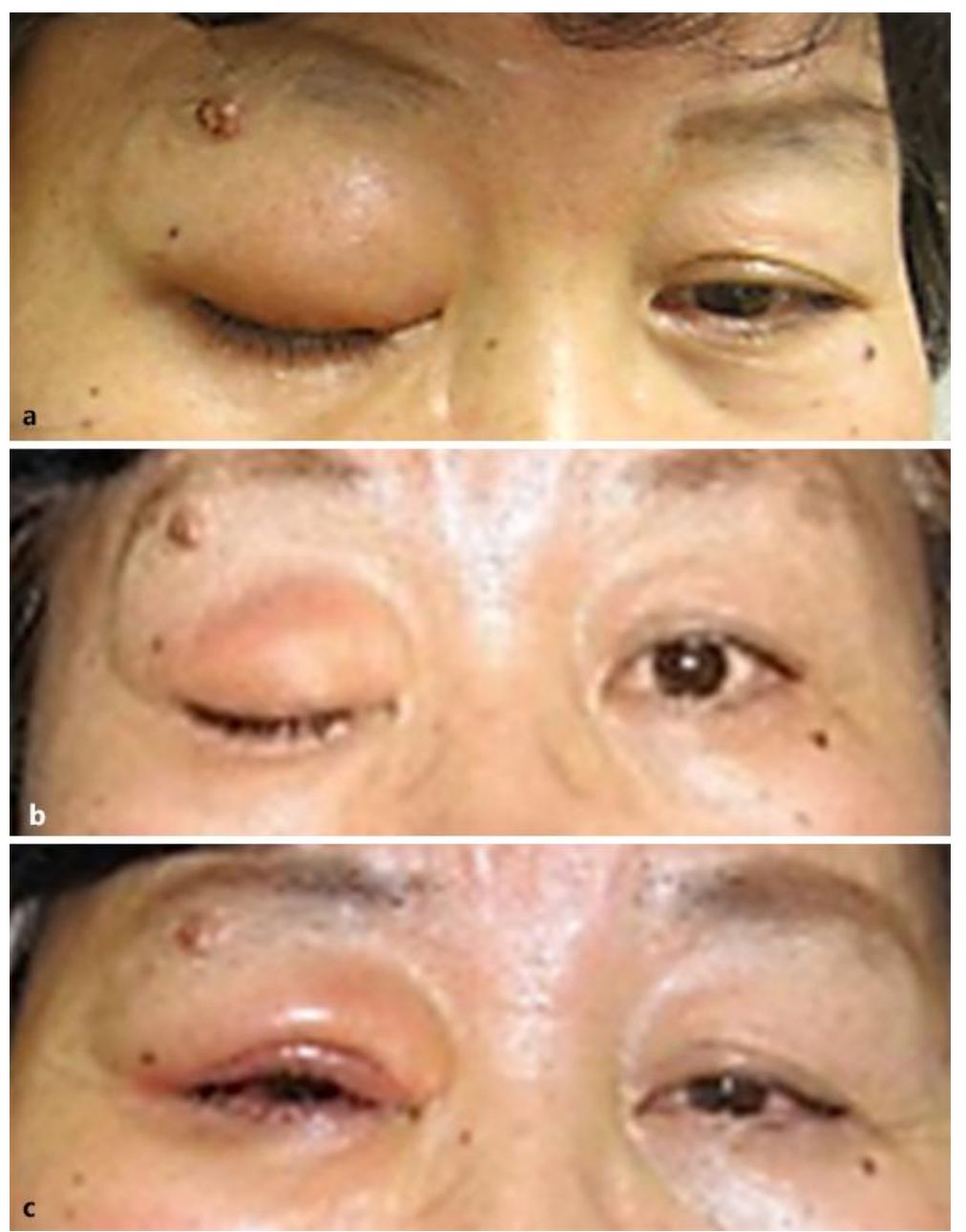

Fig. 1. a Photograph taken 3 months after reinjection of silicone oil. Note the swollen, erythematous right upper eyelid with ptosis. b Photograph taken after silicone oil removal. Although the right upper eyelid swelling has decreased, there is no improvement of the ptosis. c Photograph taken after plastic surgery. The right upper lid abnormality has resolved. 


\section{Case Reports in Ophthalmology}

\begin{tabular}{l|l}
\hline Case Rep Ophthalmol 2014;5:226-230 \\
\hline DOI: 10.1159/000365647 & $\begin{array}{l}\text { ○ 2014 S. Karger AG, Basel } \\
\text { www.karger.com/cop }\end{array}$ \\
\hline
\end{tabular}

Deguchi et al.: Migration of Intraocular Silicone Oil from the Vitreous Cavity into the Upper Eyelid Causing Ptosis

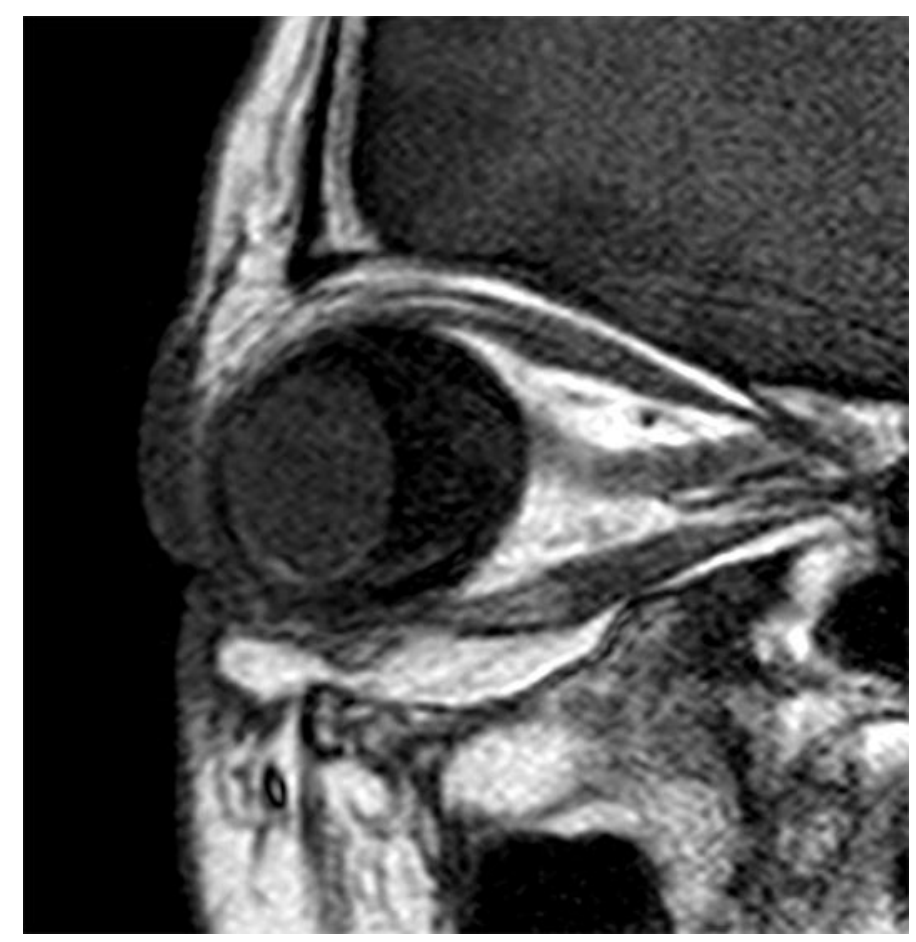

Fig. 2. Magnetic resonance imaging scan taken 6 months after reinjection of silicone oil. The T1-weighted image shows low signal intensity and the upper palpebral tissue has a moist appearance, suggesting edema or inflammation.

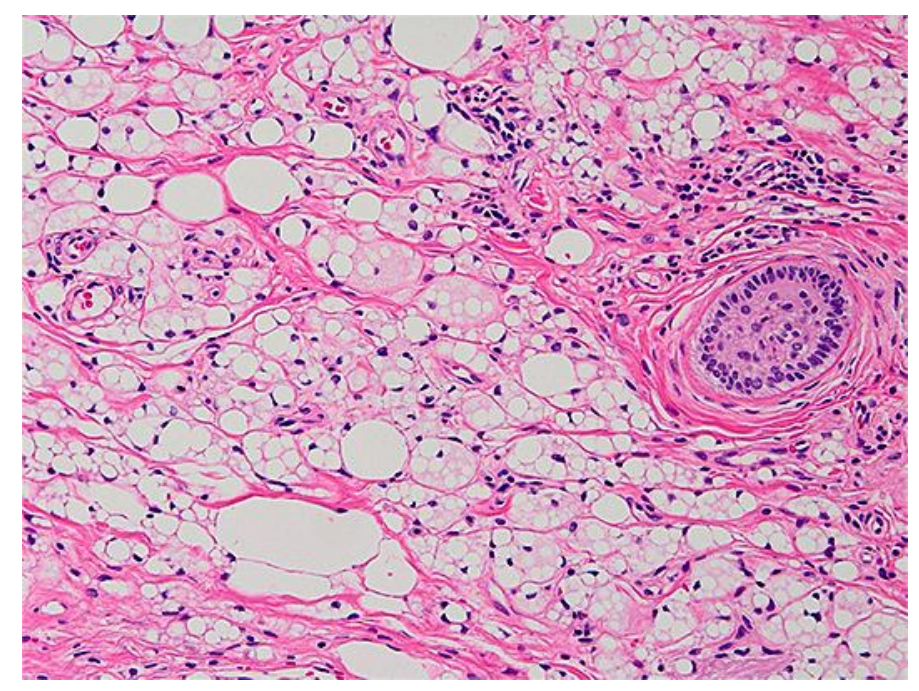

Fig. 3. Histological examination of skin and subcutaneous tissues from the upper eyelid showed a large number of lipid-like vacuoles due to silicone oil. The vacuoles were surrounded by diffuse macrophage infiltration. No apparent mass lesion was recognized in the eyelid (hematoxylin and eosin stain, $\times 20$ objective). 